\section{CHEYNE-STOKES RESPIRATION}

\section{To the Editors of THE LANCET.}

SrRs,-For some years I have had under my care an old gentleman in very comfortable circumstances whose age is now eighty-six. In childhood he had teething convulsions, from which dates external strabismus of the right eye. He has been very deaf for many years, and is now suffering from cerebral softening. About five months ago he had one afternoon three slight epileptic fits, which, however, do not seem to have affected his general condition and have not been repeated. For nearly a year he has had general anasarca, especially of the feet and legs, but no ascites. $\mathrm{He}$ sleeps well, and eats well, though he has to be fed. He is at times very irritable, and obstinate, and always speaks very loudly; he will sit for hours looking over books which he often holds upside down, although I have reason to believe the sight of the left eye is good. He has incontinence of urine and occasionally also of feces. The urine contains no albumen and no sugar, is acid, with a specific gravity of 1020. For several weeks at every visit, which I make twice a week, I have noticed very well marked Cheyne.Stokes respiration, which his nurse assures me is also present in sleep ; if excited it will cease until tranquillity is restored. After the pause the breathing begins faintly at first, and then beconies stronger and louder until it resembles that of a man who has been running, then gradually declines until it ceases entirely. The pause almost invariably lasts thirtyfive seconds; and then he breathes from nineteen to twentyone times during the next forty seconds, and this sequence continues, I have reason $t_{1}$ ) believe, throughout the day. If he speaks during the breathing space, he speaks like a man out of breath from running. I am not prepared to say whether this condition immediately followed the fits, nor can I say exactly how long it has continued. He is completely dressed every day and is carried downstairs; and, if fine, will go out for a drive or sit in his garden.

I am, Sirs, yours truly,

Plymouth, March 30th, 1890. J. EluIOT SQUARE, F.R.C.S.

\section{To the Editors of THE LANCET.}

SIRs,-Apropos of the discussion upon Cheyne-Stokes respiration going on in your columns, to show that it is not cincompatible with longevity, I would mention the following case, which, as it happens to be that of my own father, I have had special opportunity of noting, and I drew the attention to this same point of Dr. C. J. B. Williams when visitjng him as long ago as 1874, as well as Dr. Milner Fothergill, who came down to see him three years later. My father, who will shortly enter his ninety-third year, has displayed this peculiarty for many years, and apparently without any detriment or embarrassment to his vital functions. The phenonenon is marked by the usual rhythmical details, completing a cycle-viz., the gradual aloridgment of the respiratory process, the breathing becoming more and more shallow until the pause is reached, which after a short in terval is broken by four or five forced inspiratory efforts in rapid succession, as if labouring to compensate for the suspended function and to rednce the arrears of carbonic acid accumulation. I may mention that, beyond occasional syncope and vertigo, from brain shrinkage and other senile changes, the cerebral condition generally seems unimpaired, and his mental activity is of a high order for his time of life; there is nothing remarkable in the circulatory system; the pulse, though of late more frequently unrhy thmical, is sometimes a steady and regular 72. His general average of respira. tions is about 24 . Ross and other neurologists appear to associate Cheyne-Stokes respiration, and rightly too, as a rule, with cerebral cardiac and renal affections, while, after his experiments with animals, Langendorff was led to believe it was due to a spasm of the arteries of the medulla; but under the circumstances such a case as the above might be regarded rather as a fitful departure from the normal condition than an actual disorder of the nervous mechanism, constituting a temporary loss of coördination of the respiratory function and possessing more elinical interest than significance. I do not observe any instance of or allusion to this phenomenon in Professor Humphry's recent work, "Old Age."

March 2 ith, 1890.
TORONTO • UNIVERSITY LIBRARY RESTORATION.

\section{To the Editors of THE LANCET.}

Sirs,-If my recollection from two visits to the University of Toronto serves me correctly, its library, which has recently been destroyed by fire, included a valuable collection of medical and surgical works. There are many authors and possessors of duplicate copies of such works in this country who have only to be reminded of the severe loss the colonial university has sustained to desire to be included in the list of donors to the new library. I have no doubt that the hon. secretary to the Toronto University Library Restoration, 13, King's Bench-walk, Temple, will take charge of and acknowledge any donations that may be sent to him. I am, Sirs, yours truly,

Lower Berkeley-street, W., March 28th, 1890. REGINALD HARRISON.

\section{DISEASE OF THE SACRO-ILTAC JOINT. To the Editors of THE LANCET.}

SIRS,-It may interest the profession to know that I again trephined the sacro-iliac joint on Sunday last at Stockport in an obscure case of eight years' standing, with a satisfactory result. The upper half of the joint was found to be carious, and a cavity was discovered behind the first portion of the rectum. On its completion the case will be published in full.-I am, Sirs, yours truly, New Cavendish-street, W., April 1st, 1890. MAYo CoLlIER.

\section{NORTHERN COUNTIES NOTES.}

\section{(From oUR OWN CORRESPONDENT.)}

\section{Newcastle Clinical Society.}

THE meeting of the Newcastle Clinical Society on March 27th was the best, as regards attendance, of the session. Dr. Beatley presided. Dr. Ridley, hon. sec., showed cases of mastoid disease, in which trephining had been performed, with good results as to health and hearing. Dr. H. S. Baumgartner also showed a case in which the mastoid had been recently trephined, with good results; also a cyst of the broad ligament of the uterus, removed by shelling out from between the peritoneal coats of the ligament. The patient, a girl aged nineteen, made a good recovery. Mr. Adam Wilson showed a stomach with trumpet-shaped perforating ulcer of the pylorus. Dr W. Murray spoke of the value of turpentine, given in half-ounce doses, in the treatment of hæmorrhage arising in these cases, which generally occurred in anæmic females. He also read a paper on "Starving into Health," or otherwise fasting into health, in which he quoted cases of apoplexy, obesity, and dropsy, where the patient's life was evidently saved by a period of absolute starvation, extending in some cases to fourteen days. The reading of this paper, for which Dr. Murray was accorded a cordial vote of thanks, gave rise to an animated and most interesting discussion. Some of the speakers, however, as Dr. Murray pointed out, considerably diverged from the text of his paper, and got on to side lines, such as venesection and mercurial treatment, while the sole point of his paper was starvation or total abstinence from food in the treatment of various diseases. This he very fully explained by illustrative cases and analogies.

\section{The late Rev. J. H. Rutherford.}

The committee of the schools with which the late Rev. J. H. Rutberford was so intimately connected, taking into account his expressed wish and the work already done by him in the direction of extending the School of Science and Art in Newcastle as a link between the elementary schools and the University, have resolved to erect a building capable of accommodating 1200 students, with class rooms \&c. complete, to be called "The Rutherford Memorial College," at a cost of $£ 10,000$.

The Luke Armstrong Memorial Fund.

The conmittee of the Luke Armstrong Memorial Fund have issued a balance sheet and list of subscriptions, and mention is made that within three months the sum of $£ 683$ was subscribed, a proof of the estimation in which Dr. Luke 